\title{
The optimal chemotherapeutic regimen in D2-resected locally advanced gastric cancer: a propensity score-matched analysis
}

\author{
Jun Eul Hwang1,4,*, Myung Seo Ki ${ }^{1,4, *}$, Karham Kim ${ }^{1,4}$, Sung-Hoon Jung ${ }^{1,4}$, Hyun- \\ Jeong Shim ${ }^{1,4}$, Woo-Kyun Bae ${ }^{1,4}$, Eu-Chang Hwang ${ }^{2,4}$, Young Hoe Hur ${ }^{3,4}$, Oh Jeong ${ }^{3,4}$, \\ Seong Yeob Ryu ${ }^{3,4}$, Young Kyu Park ${ }^{3,4}$, Sang-Hee Cho ${ }^{1,4}$, Ju-Seog Lee ${ }^{5}$ and Ik-Joo \\ Chung ${ }^{1,4}$ \\ ${ }^{1}$ Department of Hematology-Oncology, Chonnam National University Hwasun Hospital, Jeonnam, Korea \\ 2 Department of Urology, Chonnam National University Hwasun Hospital, Jeonnam, Korea \\ ${ }^{3}$ Department of General Surgery, Chonnam National University Hwasun Hospital, Jeonnam, Korea \\ ${ }^{4}$ Chonnam National University Hwasun Hospital, Jeonnam, Korea \\ ${ }^{5}$ Department of Systems Biology, University of Texas MD Anderson Cancer Center, Houston, TX, USA \\ * These authors have contributed equally to this work as first co-authors \\ Correspondence to: Ik-Joo Chung, email: ijchung@chonnam.ac.kr
}

Keywords: gastric cancer, gastrectomy, prognosis, platinum, adjuvant chemotherapy

Received: December 22, $2016 \quad$ Accepted: March 01, $2017 \quad$ Published: March 16, 2017

Copyright: Hwang et al. This is an open-access article distributed under the terms of the Creative Commons Attribution License 3.0 (CC BY 3.0), which permits unrestricted use, distribution, and reproduction in any medium, provided the original author and source are credited.

\section{ABSTRACT}

Adjuvant chemotherapy using TS-1 or capecitabine plus oxaliplatin improves survival outcomes after radical gastrectomy, with both regimens showing similar efficacies.

A total of 494 patients with stage II-III gastric cancer who underwent curative D2 gastrectomy and received adjuvant chemotherapy from April 2004 to June 2014 were included in this study. 219 patients received TS-1, and 275 received platinum-based chemotherapy. The disease-free survival associated with adjuvant chemotherapy with TS-1 was compared with that associated with fluoropyrimidine plus platinum chemotherapy to identify the subgroups that would benefit most from platinum-based chemotherapy. The platinum group consisted of younger individuals, more males and more stage III patients compared with the TS-1 group. To reduce selection bias and its effects on treatment results, we performed a propensity scorematched analysis.

The matched cohort consisted of 219 TS-1 and 219 platinum treatment patients, respectively. In the matched cohort, the chemotherapeutic regimen did not affect disease-free survival according to stage (stage II: platinum vs. TS-1, $P=0.348$; stage III: $P=0.132$ ).

According to the subgroup analysis, platinum-based chemotherapy resulted in an improved 3-year disease-free survival compared with TS-1 treatment $(66.8 \%$ vs. $57.8 \%, P=0.015$ ) for patients with high-risk features (any two or more of pT4, pN3, and lymphovascular invasion positivity).

Our results suggest that TS-1 alone is acceptable for patients without high-risk features, while platinum-based adjuvant chemotherapy should be administered to patients with high-risk features in D2-resected gastric cancer.

\section{INTRODUCTION}

Gastric cancer is the third leading cause of cancer- related mortality worldwide, and in Korea, despite its decreasing incidence and mortality, gastric cancer remains the most common cancer in men and the third most frequent cause of cancer death in both sexes [1-3]. 
The only curative treatment for gastric cancer is surgery. Recent trials (CLASSIC and the Japanese ACTSGC trial) demonstrated that adjuvant chemotherapy involving TS-1 or capecitabine plus oxaliplatin (CAPOX) after gastrectomy with D2 lymph node dissection resulted in improved disease-free survival (DFS) and overall survival (OS) compared with surgery alone in patients with stage II or III gastric cancer [4-8]. These two adjuvant chemotherapy regimens also demonstrated similar efficacies. The 3-year and 5-year OS rates were $80.1 \%$ and $71.7 \%$, respectively, in the TS- 1 trial and the 3 -year DFS and 5-year OS rates were 74\% and 78\%, respectively, in the CAPOX trial. According to the subgroup analysis, CAPOX resulted in a significantly improved OS rate based on an increase in nodal status (N0: hazard ratio [HR] 0.79, $95 \%$ confidence interval [CI] $0.32-1.95 ; \mathrm{N} 1$ or N2, HR $0.67,95 \%$ CI $0.51-0.87)$. However, the efficacy of TS-1 was somewhat decreased in patients with N2 nodal status (N0: HR 0.317, 95\% CI 0.127-0.790; N1: HR 0.608, 95\% CI $0.440-0.840$; N2: HR $0.839,95 \%$ CI $0.612-1.1150$ ) $[5,7]$.

In this single-center study, we analyzed the efficacy of TS-1 and platinum-based adjuvant chemotherapy regimens (platinum group: CAPOX and 5-fluorouracil [5$\mathrm{FU}]$ plus cisplatin [FP]) in patients with D2-resected stage II or III gastric cancer to identify the subgroup that would benefit most from TS-1 or platinum-based chemotherapy.

\section{RESULTS}

Descriptive statistics related to the patient, tumor, and treatment characteristics for the entire cohort $(\mathrm{n}=$

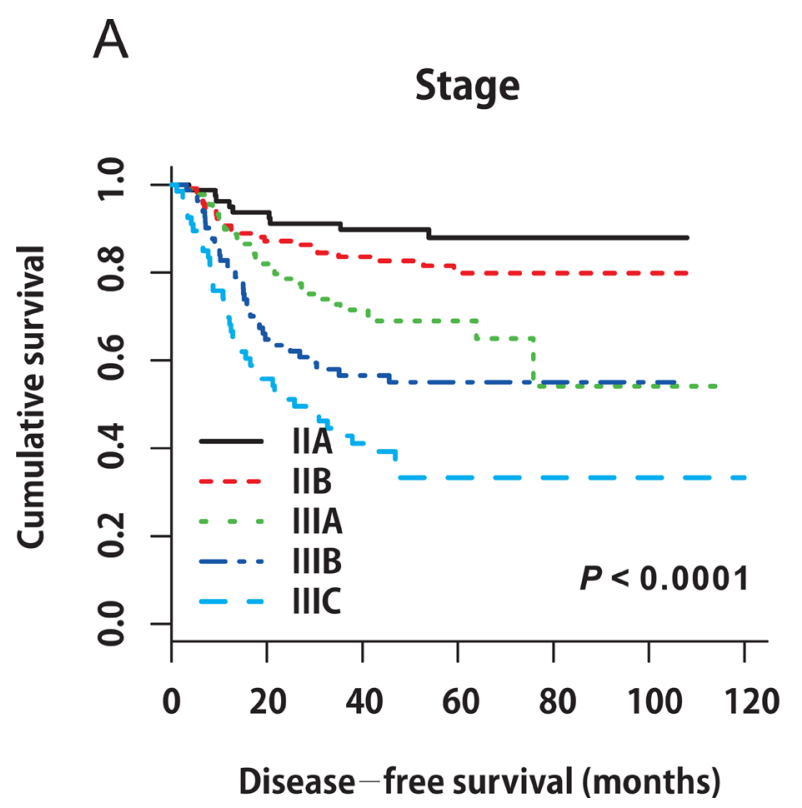

494), as well as the propensity score-matched cohort $(\mathrm{n}=$ 438), are summarized in Table 1 and 2.

\section{Entire cohort}

Among the entire cohort, the platinum group, compared with the TS-1 group, comprised younger patients (age $<59$ years: $54.9 \%$ vs. $40.6 \%$ ), more males (73.5\% vs. $64.4 \%)$, and more stage III patients $(65.5 \%$ vs. $52.1 \%$ ). A total of 275 patients received the platinumbased regimen, of whom $54(19.6 \%)$ patients received CAPOX and $221(80.4 \%)$ FP. All patients in the TS-1 group received TS-1. The median numbers of delivered cycles of FP, CAPOX, and TS-1 chemotherapy were 6 (range $1-6$, mean $5.37 \pm 1.372$ ), 8 (range $1-8$, mean $7.137 \pm 2.210$ ), and 8 (range $1-8$, mean $6.927 \pm 2.340$ ), respectively. The two groups were similar in terms of tumor location, tumor grade, Lauren classification, pT stage, $\mathrm{pN}$ stage, lymphovascular invasion (LVI), and perineural invasion.

The median follow-up period was 53.9 months (range 1.5-119.9 months) in the platinum group and 48.2 months (range 2.4-95.8 months) in the TS-1 group. In total, 164 events occurred: $90(18.2 \%)$ in the platinum group and $74(15 \%)$ in the TS-1 group. Distinct DFS curves were apparent according to stage $(P<0.0001$, IIA-IIIB: median DFS, not reached; IIIC: median DFS 23.3 months, 95\% CI 10.872-35.728). There was no statistically significant difference in DFS between the platinum and TS-1 groups in the entire cohort $(P=0.506)$. In the subgroup analysis, there were no differences in survival between the two groups according to stage (stage

B

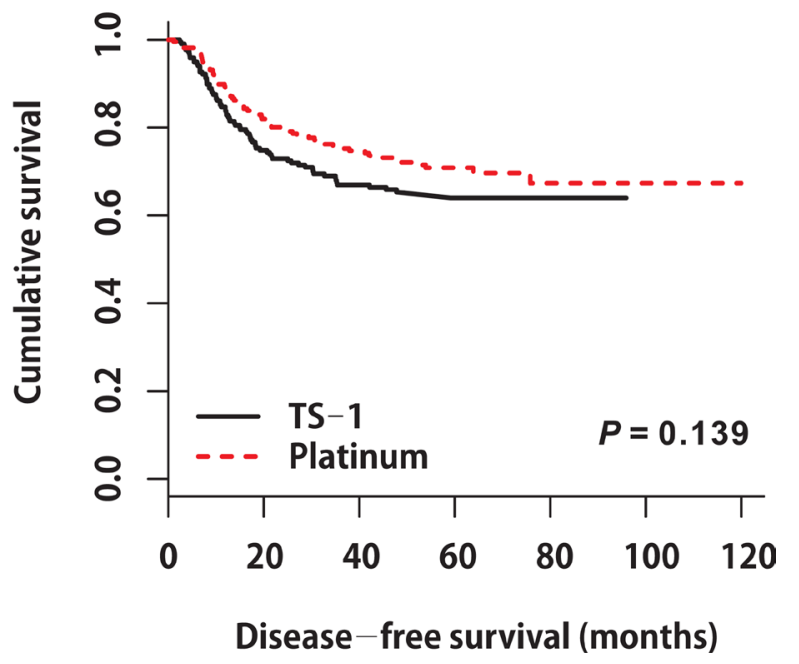

Figure 1: A. Disease-free survival curves stratified by stage in the propensity score-matched cohort $(P<0.0001$, IIA-IIIB: median DFS not reached; IIIC: median DFS 25.767 months, 95\% CI 10.190-41.344). B. Disease-free survival curves stratified by adjuvant chemotherapy in the propensity score-matched cohort $(P=0.139)$. 
Table 1: Baseline characteristics of the patients in the entire cohort $(n=494)$ stratified by adjuvant chemotherapy (platinum group vs. TS-1 group).

\begin{tabular}{|c|c|c|c|}
\hline \multirow[b]{2}{*}{ Variable } & \multicolumn{3}{|c|}{ Entire cohort } \\
\hline & Platinum group $(\mathrm{n}=\mathbf{2 7 5})$ & TS-1 $(n=219)$ & $\boldsymbol{P}$ \\
\hline Age, years & & & 0.002 \\
\hline$<59$, n. $(\%)$ & $151(54.9)$ & $89(40.6)$ & \\
\hline$\geq 59, \mathrm{n} .(\%)$ & $124(45.1)$ & $130(59.4)$ & \\
\hline \multicolumn{4}{|l|}{ Regimen } \\
\hline CAPOX & $54(19.6)$ & TS-1 (100) & \\
\hline FP & $221(80.4)$ & & \\
\hline Sex & & & 0.030 \\
\hline Male, n. $(\%)$ & $202(73.5)$ & $141(64.4)$ & \\
\hline Female, n. $(\%)$ & $73(26.5)$ & $78(35.6)$ & \\
\hline Tumor location & & & 0.901 \\
\hline GEJ, whole stomach & $59(21.5)$ & 48 (21.9) & \\
\hline body, antrum & $216(78.5)$ & $171(78.1)$ & \\
\hline Tumor grade & & & 0.490 \\
\hline well/moderately differentiated & $80(29.1)$ & $70(32)$ & \\
\hline poorly/un-differentiated & $195(70.9)$ & $149(68)$ & \\
\hline Lauren classification & & & 0.832 \\
\hline intestinal & $137(49.8)$ & $107(48.9)$ & \\
\hline non-intestinal (diffuse or mixed) & $138(50.2)$ & $112(51.1)$ & \\
\hline AJCC stage & & & 0.003 \\
\hline II & $95(34.5)$ & $105(47.9)$ & \\
\hline IIA/IIB & $35(12.7) / 60(21.8)$ & $47(21.5) / 58(26.5)$ & \\
\hline III & $180(65.5)$ & $114(52.1)$ & \\
\hline IIIA/IIIB/IIIC & $63(22.9) / 69(25.1) / 48(17.5)$ & $42(19.2) / 33(15.1) / 39(17.8)$ & \\
\hline T stage & & & 0.354 \\
\hline $\mathrm{T} 1$ & $9(3.3)$ & $10(4.6)$ & \\
\hline $\mathrm{T} 2$ & $37(13.5)$ & $33(15.1)$ & \\
\hline $\mathrm{T} 3$ & $102(37.1)$ & $92(42)$ & \\
\hline $\mathrm{T} 4$ & $127(46.2)$ & $84(38.4)$ & \\
\hline N stage & & & 0.309 \\
\hline No & $35(12.7)$ & $39(17.8)$ & \\
\hline N1 & $66(24.0)$ & $57(26.0)$ & \\
\hline $\mathrm{N} 2$ & $81(29.5)$ & $61(27.9)$ & \\
\hline N3 & $93(33.8)$ & $62(28.3)$ & \\
\hline LVI + & $167(60.7)$ & $122(55.7)$ & 0.261 \\
\hline PNI+ & $198(72.0)$ & $160(73.1)$ & 0.793 \\
\hline
\end{tabular}

5-FU 5-fluorouracil, GEJ gastroesophageal junction, LVI lymphovascular invasion, PNI perineural invasion

All patients median age (interquartile range, IQR): 59 (49-69) 
Table 2: Baseline characteristics of the patients in the propensity score-matched cohort $(n=438)$ stratified by adjuvant chemotherapy (platinum group vs. TS-1 group).

\begin{tabular}{|c|c|c|c|}
\hline \multirow[b]{2}{*}{ Variable } & \multicolumn{3}{|c|}{ Propensity score-matched cohort } \\
\hline & Platinum group $(n=219)$ & TS-1 $(n=219)$ & $P$ \\
\hline Age, years & & & 0.628 \\
\hline$<59$, n. $(\%)$ & $95(43.4)$ & $89(40.6)$ & \\
\hline$\geq 59$, n. $(\%)$ & $124(56.6)$ & $130(59.4)$ & \\
\hline \multicolumn{4}{|l|}{ Regimen } \\
\hline CAPOX & $43(19.6)$ & TS-1 (100) & \\
\hline FP & $176(80.4)$ & & \\
\hline Sex & & & 0.152 \\
\hline Male, n. (\%) & $156(71.2)$ & $141(64.4)$ & \\
\hline Female, n. $(\%)$ & $63(28.8)$ & $78(35.6)$ & \\
\hline \multicolumn{4}{|l|}{ Tumor location } \\
\hline GEJ, whole stomach & $43(19.6)$ & $48(21.9)$ & 0.638 \\
\hline body, antrum & $176(80.4)$ & $171(78.1)$ & \\
\hline Tumor grade & & & 0.838 \\
\hline well/moderately differentiated & $72(32.9)$ & $70(32)$ & \\
\hline poorly/un-differentiated & $147(67.1)$ & $149(68)$ & \\
\hline \multicolumn{4}{|l|}{ Lauren classification } \\
\hline intestinal & $119(54.3)$ & $107(48.9)$ & 0.293 \\
\hline non-intestinal (diffuse or mixed) & $100(45.7)$ & $112(51.1)$ & \\
\hline AJCC stage & & & 0.388 \\
\hline II & $95(43.4)$ & $105(47.9)$ & \\
\hline IIA/IIB & $35(16.0) / 60(27.4)$ & $47(21.5) / 58(26.5)$ & \\
\hline III & $124(56.6)$ & $114(52.1)$ & \\
\hline IIIA/IIIB/IIIC & $47(21.5) / 49(22.4) / 28(12.8)$ & $42(19.2) / 33(15.1) / 39(17.8)$ & \\
\hline T stage & & & 0.851 \\
\hline $\mathrm{T} 1$ & $9(4.1 \%)$ & $10(4.6 \%)$ & \\
\hline $\mathrm{T} 2$ & $34(15.5 \%)$ & $33(15.1 \%)$ & \\
\hline $\mathrm{T} 3$ & $84(38.4 \%)$ & $92(42.0 \%)$ & \\
\hline $\mathrm{T} 4$ & $92(42.0 \%)$ & $84(38.4 \%)$ & \\
\hline $\mathrm{N}$ stage & & & 0.915 \\
\hline N0 & $34(15.5 \%)$ & $39(17.8 \%)$ & \\
\hline N1 & $61(27.9 \%)$ & $57(26.0 \%)$ & \\
\hline N2 & $63(28.8 \%)$ & $61(27.9 \%)$ & \\
\hline N3 & $61(27.9 \%)$ & $62(28.3 \%)$ & \\
\hline $\mathrm{LVI}+$ & $125(57.1 \%)$ & $122(55.7 \%)$ & 0.847 \\
\hline $\mathrm{PNI}+$ & $147(67.1 \%)$ & $160(73.1 \%)$ & 0.210 \\
\hline
\end{tabular}

5-FU 5-fluorouracil, GEJ gastroesophageal junction, $L V I$ lymphovascular invasion, PNI perineural invasion All patients median age (interquartile range, IQR): 59 (49-69) 
Table 3: Univariate and multivariate analyses of risk factors for disease-free survival in the propensity score-matched cohort $(n=438)$.

\begin{tabular}{lccccc}
\hline \multirow{2}{*}{ Variables } & \multicolumn{2}{c}{ Univariate analysis } & & \multicolumn{2}{c}{ Multivariate analysis } \\
\cline { 2 - 3 } \cline { 5 - 6 } & HR (95\% CI) & $\boldsymbol{P}$ & & HR (95\% CI) & $\boldsymbol{P}$ \\
\cline { 2 - 3 } Age $\geq 59$, n.(\%) & $1.553(1.094-2.205)$ & 0.014 & & $1.415(0.979-2.044)$ & 0.064 \\
Male, n. (\%) & $1.168(0.812-1.680)$ & 0.403 & & $1.476(1.010-2.157)$ & 0.044 \\
Tumor location & & & & & \\
$\quad$ GEJ, whole stomach & $1.133(0.756-1.699)$ & 0.545 & & & \\
Lauren classification & & & & & \\
$\quad$ non-intestinal (diffuse or mixed) & $1.252(0.895-1.753)$ & 0.189 & & & \\
TS-1 & $1.289(0.920-1.804)$ & 0.14 & & $1.288(0.915-1.811)$ & 0.146 \\
T3+T4 & $2.704(1.526-4.789)$ & 0.001 & & $2.799(1.531-5.116)$ & 0.001 \\
N2+N3 & $3.188(2.135-4.760)$ & 0.0001 & & $2.999(1.981-4.540)$ & 0.0001 \\
LVI+ & $1.697(1.190-2.420)$ & 0.003 & & $1.581(1.089-2.296)$ & 0.016 \\
PNI+ & $1.435(0.970-2.123)$ & 0.071 & & & \\
\hline
\end{tabular}

$G E J$ gastroesophageal junction

II: platinum $v s$. TS- $1, P=0.348$; stage III: $P=0.190$ ), pT stage, pN stage, or LVI status.

\section{Propensity score-matched cohort}

Propensity score matching resulted in 219 matched pairs for a total of 438 patients. None of the clinical variables were significantly different between groups of matched pairs, indicating that the matching procedure was successful (Table 2).

In the matched cohort, the median follow-up period was 55.0 months (range 1.5-119.9 months) in the platinum group and 48.2 months (range 2.4-95.8 months) in the TS-1 group. In total, 137 events occurred: $63(14.4 \%)$ in the platinum group and $74(16.9 \%)$ in the TS-1 group. Distinct DFS curves were apparent according to stage (Figure 1A, $P<0.0001$, IIA-IIIB: median DFS not reached; IIIC: median DFS 25.767 months, $95 \%$ CI 10.190-41.344). The DFS curves did not differ between the platinum and TS-1 groups in the propensity scorematched population. The 3 -year DFS rate was $84.8 \%$ in the platinum group and $66.9 \%$ in the TS- 1 group (Figure $1 \mathrm{~B}, P=0.139)$. In the multivariate analysis, advanced $\mathrm{T}$ stage (pT3+pT4), advanced nodal status ( $\mathrm{pN} 2+\mathrm{pN} 3)$, and LVI positivity (LVI+) were identified as poor prognostic clinical variables for DFS (Table 3). In the subgroup analysis, there was no difference in survival between the two groups according to stage (Figure 2A, 2B, stage II: platinum $v s$. TS-1, $\mathrm{p}=0.348$; stage III: platinum $v s$. TS-1, $P=0.132$, median DFS, not reached $v s .45 .63$ months). However, platinum-based chemotherapy resulted in improved DFS in patients with pT4 tumors (Figure 2C, $P=0.033$, platinum $v s$. TS-1, median DFS, not reached vs. 47.83 months) and in patients with combined stage
III and LVI+ tumors (Figure 2D, $P=0.029$, platinum vs. TS-1, median DFS, not reached vs. 30.267 months, $95 \%$ CI 6.650-53.883). In patients with $\mathrm{pN} 3$ nodal status, platinum-based chemotherapy resulted in marginally improved DFS compared with TS-1 (Figure 2E, $P=$ 0.073 , platinum vs. TS- 1 , median DFS, 75.8 months, 95\% CI 33.551-118.049, vs. 21.767 months, 95\% CI 7.367-36.166).

Based on these findings, we constructed DFS curves according to the existence of pT4, pN3, and LVI+ (Figure $3 \mathrm{~A}, P<0.0001)$. We found that patients with high-risk features (two or more of pT4, pN3, and LVI+) had better DFS when they received platinum-based chemotherapy (Figure 3B, platinum $v s$. TS-1, median DFS: not reached vs. 30.4 months, $95 \%$ CI 9.499-51.301, $P=0.015$ ). The 3 -year DFS rate of patients with high-risk features was $66.8 \%$ in the platinum group and $57.8 \%$ in the TS- 1 group. High-risk patients benefited the most from platinum-based chemotherapy (Figure 4, HR 0.578, 95\% CI 0.371-0.9, $P$ $=0.015$ ).

\section{DISCUSSION}

Gastric cancer disseminates early via the lymphatic system, blood, and peritoneum. Recurrences or metastasis after surgery are common, and if they occur, the disease has a very dismal prognosis $[9,10]$. Several attempts to reduce tumor recurrence have been made over the past decades using perioperative chemotherapy, postoperative chemoradiation, and chemotherapy [11-14]. Two recent adjuvant chemotherapy trials (CLASSIC and the Japanese ACTS-GC trial) of CAPOX and TS-1 demonstrated improved DFS and OS in patients with stage II or III gastric cancer who underwent D2 gastrectomy compared with those treated with surgery alone, and these results 

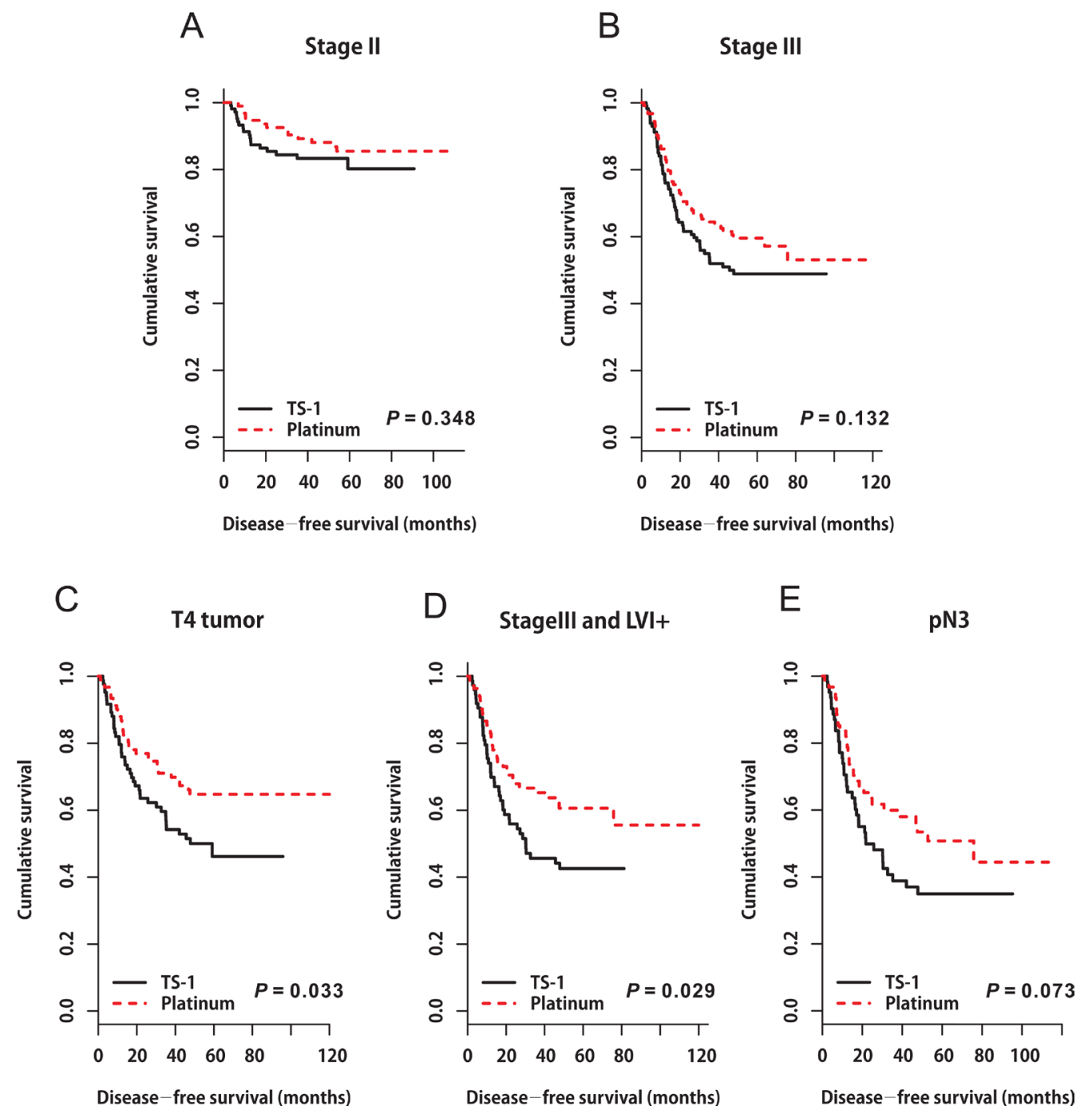

Figure 2: Disease-free survival curves stratified by adjuvant chemotherapy in patients with $\mathbf{A}$. stage II tumors $(P=0.348)$, B. stage III tumors $(P=0.132)$, C. pT4 tumors $(P=0.033)$, D. combined stage III and LVI+ tumors $(P=0.029)$, and $\mathbf{E}$. pN3 nodal status $(P=0.073)$.

A

1,2 , or 3 of $\mathrm{pT} 4, \mathrm{pN} 3$ and LVI+

High risk (any $2 \geq$ of $\mathrm{T} 4, \mathrm{~N} 3$, and $\mathrm{LVI}+$ )
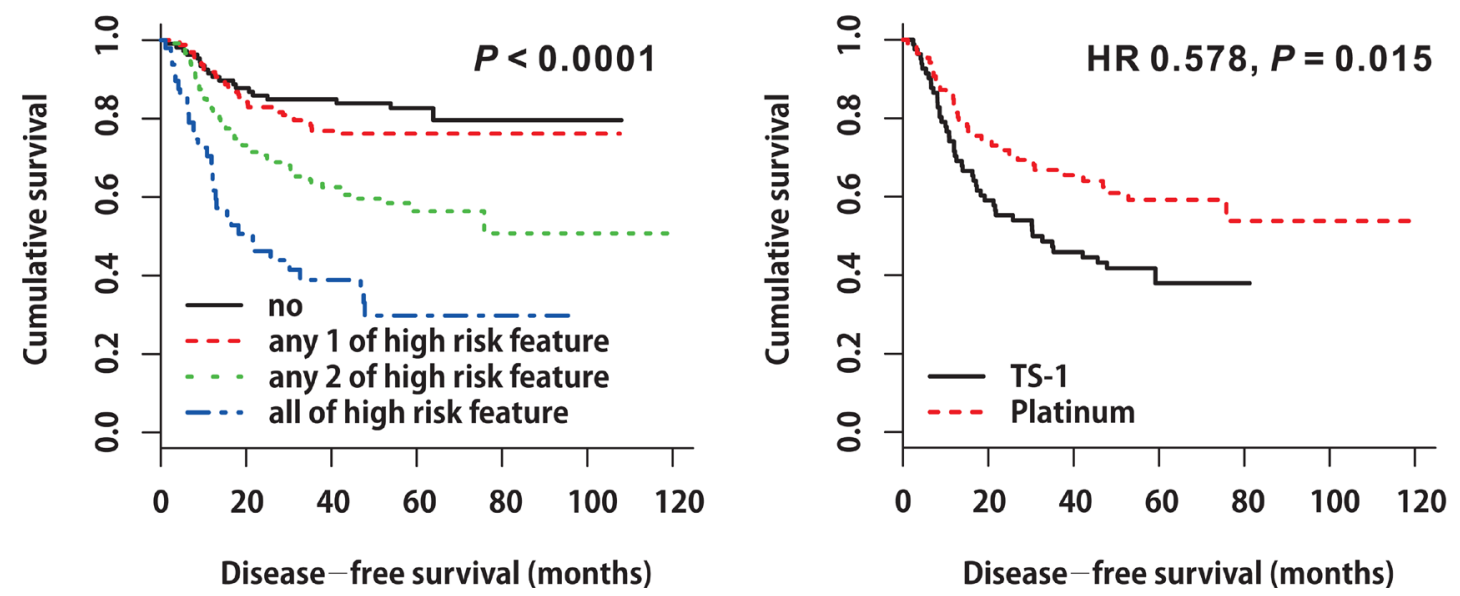

Figure 3: A. Disease-free survival curves according to the existence of pT4, pN3, and LVI $+(P<0.0001)$. B. Disease-free survival curves stratified by adjuvant chemotherapy in patients with high-risk features (two or more of pT4, pN3, and LVI + ) $(\mathrm{HR} 0.578, P=0.015$ ). 
showed similar efficacies. However, until now, it was unknown as to which subgroup would benefit most from CAPOX or TS-1 (i.e., who would benefit more from adding the platinum compound to fluoropyrimidines). In this study, we demonstrated an increased DFS after adjuvant chemotherapy with a platinum-based regimen, compared with adjuvant TS-1 chemotherapy, in patients with high-risk features (two or more of pT4, pN3, and LVI+) who underwent D2 gastrectomy.

In colon cancer, adding oxaliplatin to 5-FU and leucovorin (i.e., the FOLFOX regimen) is recommend for patients with stage III and high-risk stage II colon cancer (high-risk features: poorly differentiated histology, LVI, perineural invasion, bowel obstruction, and localized perforation) [15-17]. Similarly, in this study, we demonstrated that platinum-based chemotherapy resulted in improved DFS in patients with combined stage III and LVI+ tumors. (Figure 2D, $P=0.029$, Platinum-based chemotherapy $v s$. TS-1, median DFS, not reached $v s$. 30.267 months, 95\% CI 6.650-53.883).

A recent study reported that clinicians prefer CAPOX for younger patients and those with stage III gastric cancer; however, for elderly patients, clinicians choose TS-1 more often [18]. Similar to these findings, in this study, the platinum group, compared with the TS-1 group, was younger (age $<59$ years: $54.9 \%$ vs. $40.6 \%$ )

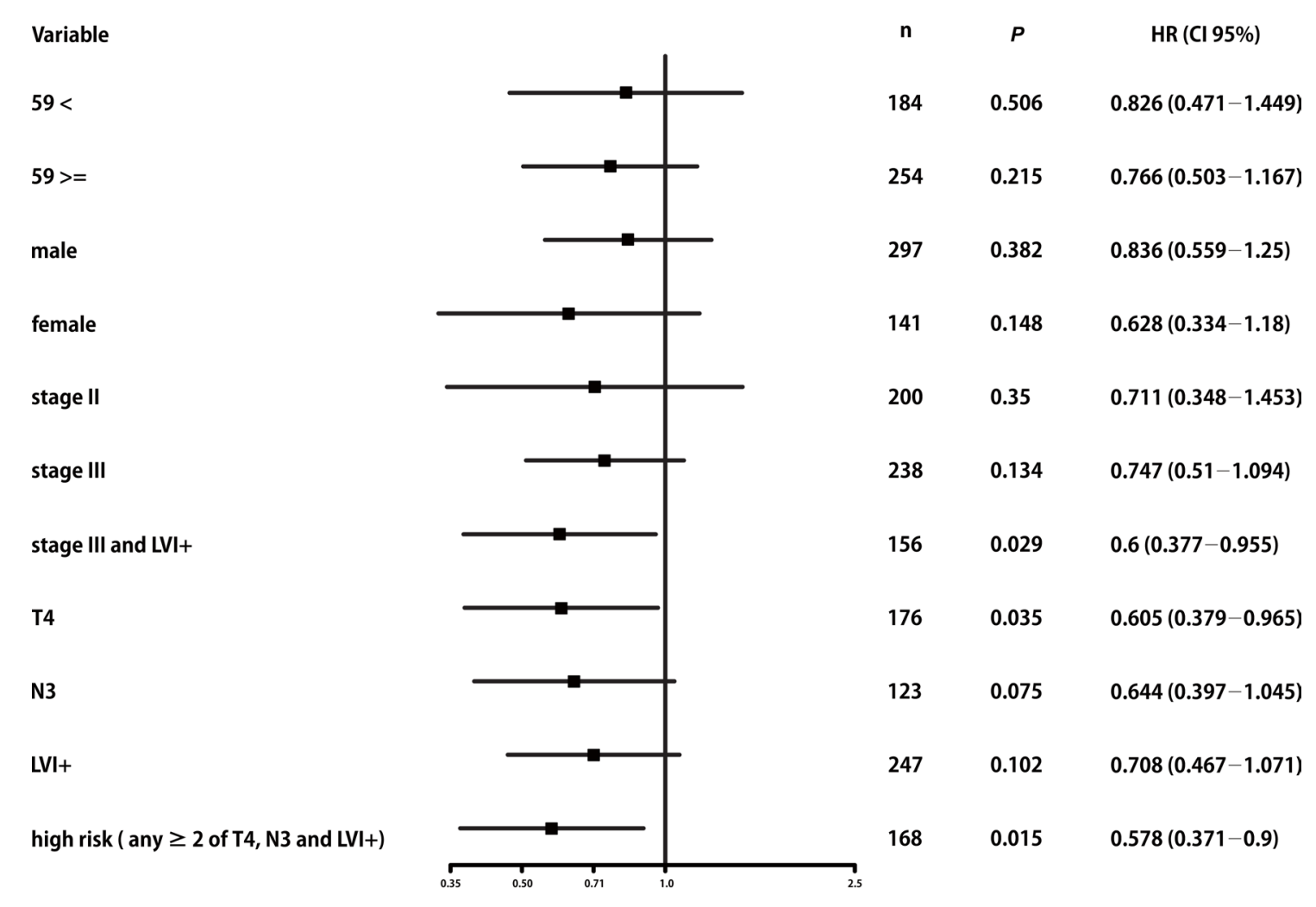

and included more stage III patients (65.5\% vs. 52.1\%). Generally, clinicians are reluctant to administer platinum to early-stage disease and elderly patients.

Doublet chemotherapy with fluoropyrimidine (5-FU or capecitabine) and platinum (cisplatin or oxaliplatin) is recommended for metastatic or locally advanced gastric cancer if the tumor is negative for HER2 amplification. In these cases, TS-1 and cisplatin, compared with TS-1 alone, resulted in improved progression-free survival (TS-1/cisplatin vs. TS-1: 6.0 vs. 4.0 months, $P<0.0001$ ) and OS (13.0 vs. 11.0 months, $P=0.04)$ [19-21]. Similar to metastatic gastric cancer, platinum-based adjuvant chemotherapy can be a better option for advancedstage and high-risk patients even in the adjuvant setting, as shown here in D2-resected gastric cancer patients with high-risk features treated with platinum-based chemotherapy.

There are several limitations to this study. This was a retrospective analysis from a single institution. We did not present the toxicities associated with each chemotherapy regimen; however, all regimens are widely used in the clinical setting, and all toxicities were manageable and did not differ from those reported in previous studies. Therefore, there were no special toxicities to report. Additionally, we did not evaluate OS. Considering the retrospective nature of this adjuvant chemotherapy study,

Favors platinum-based chemotherapy $\quad$ Favors TS-1

Figure 4: Disease-free survival stratified by adjuvant chemotherapy. High-risk patients who benefited most from platinumbased chemotherapy (HR 0.578, 95\% CI $0.371-0.9, P=0.015$ ). 
various confounding factors for OS may exist, such as loss to follow-up, the general medical conditions of the patient, and palliative chemotherapy (whether the patient received it or not after the disease recurred). According to a previous report, in patients with gastric cancer, most relapses occur within 3 years of surgery, and DFS is an acceptable surrogate endpoint in place of OS in trials of adjuvant chemotherapy for gastric cancer [22, 23]. Therefore, investigation of DFS was justified in this adjuvant chemotherapy study.

In conclusion, TS-1 alone is acceptable for D2resected gastric cancer patients without high-risk features, while platinum-based adjuvant chemotherapy should be considered for patients with high-risk features, especially stage III patients. These findings should be further confirmed in a randomized prospective clinical trial.

\section{MATERIALS AND METHODS}

\section{Patients}

A total of 494 patients with gastric cancer received adjuvant chemotherapy after D2 gastrectomy between April 2005 and June 2014 at the Chonnam National University Hwasun Hospital in Jeonnam, Republic of Korea. Patients with no adjuvant chemotherapy after surgery for any reason $(n=137)$, other co-existing cancers $(\mathrm{n}=9)$, palliative resection $(\mathrm{n}=77)$, and pathologic evidence of distant metastasis $(n=40)$ were excluded. The inclusion criteria were as follows: histologically confirmed stage II or III gastric adenocarcinoma according to the American Joint Committee on Cancer, $7^{\text {th }}$ edition, no evidence of distant metastasis, $\mathrm{R} 0$ resection (with no tumor cells in the surgical margin), D2 lymph node dissection, and no previous cancer treatment. All data were collected from our institutional data base, and the survival data were updated at the time of analysis. This study was approved by the Institutional Review Board of Chonnam National University Medical School Research Institution, which waived the requirement for written informed consent from the patients due to the retrospective nature of this study.

\section{Adjuvant chemotherapy}

Adjuvant chemotherapy was administered using TS-1 (Taiho Pharmaceutical, Tokyo, Japan), FP, or CAPOX according to the physician's judgment and patient's preference. The FP regimen was used most commonly, because the Korea National Health Insurance Service did not reimburse for the CAPOX regimen prior to March 2013. Since April 2013, CAPOX has been used instead of FP due to insurance reimbursement from the Korea National Health Insurance Service. The dose of TS-1 was determined based on the body surface area
(BSA). Accordingly, patients received one of the following doses, divided into two, after meals daily: $80 \mathrm{mg}$ for patients with a BSA $<1.25 \mathrm{~m}^{2}, 100 \mathrm{mg}$ for those with a BSA of $1.25-1.49 \mathrm{~m}^{2}$, and $120 \mathrm{mg}$ for those with a BSA $\geq$ $1.50 \mathrm{~m}^{2}$. TS-1 was administered for 4 weeks followed by a 2 -week break. Treatment was continued for 1 year after surgery. The FP regimen was as follows: 5-FU (800 mg/ $\mathrm{m}^{2}$ per day) was administered by continuous intravenous infusion on days $1-5$ of each cycle, and cisplatin $(80 \mathrm{mg} /$ $\mathrm{m}^{2}$ ) was administered by intravenous infusion on day 1 . The FP regimen was administered every 4 weeks for 6 cycles. The CAPOX regimen was administered over eight 3 -week cycles, consisting of capecitabine $\left(1000 \mathrm{mg} / \mathrm{m}^{2}\right.$ twice daily on days 1-14 of each cycle) plus intravenous oxaliplatin $\left(130 \mathrm{mg} / \mathrm{m}^{2}\right.$ on day 1 of each cycle). The management of adverse events and subsequent dose reductions of the chemotherapeutic agents were performed according to a conventional protocol.

\section{Follow-up}

To assess tumor recurrence, abdominal computed tomography was performed every 3 months during the first 2 years after surgery and every 6 months thereafter until 5 years after surgery. Physical examination, chest radiography, and measurements of carcinoembryonic antigen and carbohydrate antigen 19-9 tumor markers were performed every 3 months for the first 2 years and every 6 months thereafter until 5 years. If clinical signs or symptoms indicated possible recurrence or the development of a new gastric cancer, an investigation was conducted to verify whether the patient was disease-free.

\section{Statistical analysis}

Statistically significant differences were assessed using the Chi squared test or Fisher's exact test for categorical data. The t-test or Mann-Whitney $U$ test was used for continuous data. Since patients were not randomly assigned to receive postoperative adjuvant TS-1 or platinum-based chemotherapy (platinum group: FP or CAPOX), it was highly likely that the two patient groups would have significant baseline differences that could confound the final outcome analysis. To reduce the effects of selection bias and potential confounding factors, such as uneven patient distribution between the TS-1 and platinum group, we used 1:1 propensity score matching to adjust for age, sex, and stage.

DFS was defined as the time from the date of surgery to the detection of recurrent disease or death, whichever occurred first. If neither event occurred at the time of analysis, the patient was censored. Survival curves were generated using the Kaplan-Meier method, and a survival comparison was performed using the log-rank test. Factors associated with DFS were determined by univariate and 
multivariate Cox proportional hazard regression models with hazard ratios (HRs) and 95\% confidence intervals (CIs). All statistical analyses were performed using SPSS version 21.0 (IBM Corporation, Armonk, NY, USA) and the program R (R Foundation for Statistical Computing, Vienna, Austria, http://www.R-project.org). All p values are two-sided, with $\mathrm{p}<0.05$ considered statistically significant.

\section{CONFLICTS OF INTEREST}

The authors have no conflict of interest.

\section{GRANT SUPPORT}

This work was supported by a research grant from the Research Institute of Medical Sciences, Chonnam National University (2014-CURIMS-OR024).

\section{REFERENCES}

1. Jung KW, Won YJ, Kong HJ, Oh CM, Cho H, Lee DH, Lee KH. Cancer statistics in Korea: incidence, mortality, survival, and prevalence in 2012. Cancer Res Treat. 2015; 47:127-141.

2. Siegel RL, Miller KD, Jemal A. Cancer statistics, 2016. CA Cancer J Clin. 2016; 66:7-30.

3. Torre LA, Bray F, Siegel RL, Ferlay J, Lortet-Tieulent J, Jemal A. Global cancer statistics, 2012. CA Cancer J Clin. 2015; 65:87-108.

4. Sakuramoto S, Sasako M, Yamaguchi T, Kinoshita T, Fujii M, Nashimoto A, Furukawa H, Nakajima T, Ohashi Y, Imamura H, Higashino M, Yamamura Y, Kurita A, et al. Adjuvant chemotherapy for gastric cancer with S-1, an oral fluoropyrimidine. N Engl J Med. 2007; 357:1810-1820.

5. Sasako M, Sakuramoto S, Katai H, Kinoshita T, Furukawa H, Yamaguchi T, Nashimoto A, Fujii M, Nakajima T, Ohashi Y. Five-year outcomes of a randomized phase III trial comparing adjuvant chemotherapy with S-1 versus surgery alone in stage II or III gastric cancer. J Clin Oncol. 2011; 29:4387-4393.

6. Bang YJ, Kim YW, Yang HK, Chung HC, Park YK, Lee KH, Lee KW, Kim YH, Noh SI, Cho JY, Mok YJ, Kim YH, Ji J, et al. Adjuvant capecitabine and oxaliplatin for gastric cancer after D2 gastrectomy (CLASSIC): a phase 3 openlabel, randomised controlled trial. Lancet. 2012; 379:315321.

7. Noh SH, Park SR, Yang HK, Chung HC, Chung IJ, Kim SW, Kim HH, Choi JH, Kim HK, Yu W, Lee JI, Shin DB, Ji J, et al. Adjuvant capecitabine plus oxaliplatin for gastric cancer after D2 gastrectomy (CLASSIC): 5-year follow-up of an open-label, randomised phase 3 trial. Lancet Oncol. 2014; 15:1389-1396.

8. Gallo A, Cha C. Updates on esophageal and gastric cancers.
World J Gastroenterol. 2006; 12:3237-3242.

9. Wu CW, Lo SS, Shen KH, Hsieh MC, Chen JH, Chiang JH, Lin HJ, Li AF, Lui WY. Incidence and factors associated with recurrence patterns after intended curative surgery for gastric cancer. World J Surg. 2003; 27:153-158.

10. D’Angelica M, Gonen M, Brennan MF, Turnbull AD, Bains M, Karpeh MS. Patterns of initial recurrence in completely resected gastric adenocarcinoma. Ann Surg. 2004; 240:808816.

11. Ychou M, Boige V, Pignon JP, Conroy T, Bouche O, Lebreton G, Ducourtieux M, Bedenne L, Fabre JM, SaintAubert B, Geneve J, Lasser P, Rougier P. Perioperative chemotherapy compared with surgery alone for resectable gastroesophageal adenocarcinoma: an FNCLCC and FFCD multicenter phase III trial. J Clin Oncol. 2011; 29:17151721.

12. Cunningham D, Allum WH, Stenning SP, Thompson JN, Van de Velde CJ, Nicolson M, Scarffe JH, Lofts FJ, Falk SJ, Iveson TJ, Smith DB, Langley RE, Verma M, et al. Perioperative chemotherapy versus surgery alone for resectable gastroesophageal cancer. N Engl J Med. 2006; 355:11-20.

13. Macdonald JS, Smalley SR, Benedetti J, Hundahl SA, Estes NC, Stemmermann GN, Haller DG, Ajani JA, Gunderson LL, Jessup JM, Martenson JA. Chemoradiotherapy after surgery compared with surgery alone for adenocarcinoma of the stomach or gastroesophageal junction. N Engl J Med. 2001; 345:725-730.

14. Park SH, Sohn TS, Lee J, Lim DH, Hong ME, Kim KM, Sohn I, Jung SH, Choi MG, Lee JH, Bae JM, Kim S, Kim ST, et al. Phase III Trial to Compare Adjuvant Chemotherapy With Capecitabine and Cisplatin Versus Concurrent Chemoradiotherapy in Gastric Cancer: Final Report of the Adjuvant Chemoradiotherapy in Stomach Tumors Trial, Including Survival and Subset Analyses. J Clin Oncol. 2015; 33:3130-3136.

15. André $\mathrm{T}$, Boni $\mathrm{C}$, Mounedji-Boudiaf L, Navarro $\mathrm{M}$, Tabernero J, Hickish T, Topham C, Zaninelli M, Clingan P, Bridgewater J, Tabah-Fisch I, de Gramont A, Multicenter International Study of Oxaliplatin/5-Fluorouracil/ Leucovorin in the Adjuvant Treatment of Colon Cancer (MOSAIC) Investigators. Oxaliplatin, fluorouracil, and leucovorin as adjuvant treatment for colon cancer. N Engl J Med. 2004; 350:2343-2351.

16. André T, Boni C, Navarro M, Tabernero J, Hickish T, Topham C, Bonetti A, Clingan P, Bridgewater J, Rivera F, de Gramont A. Improved overall survival with oxaliplatin, fluorouracil, and leucovorin as adjuvant treatment in stage II or III colon cancer in the MOSAIC trial. J Clin Oncol. 2009; 27:3109-3116.

17. Gill S, Loprinzi CL, Sargent DJ, Thomé SD, Alberts SR, Haller DG, Benedetti J, Francini G, Shepherd LE, Francois Seitz J, Labianca R, Chen W, Cha SS, et al. Pooled analysis of fluorouracil-based adjuvant therapy for stage II and III colon cancer: who benefits and by how much? J Clin Oncol. 
2004; 22:1797-1806.

18. Lee HY, Hwang IG, Park SE, Kim MJ, Park SH, Kang JH, Kim YS, Oh SY, Won YW, Lee SI, Ji JH, Chi KC. Factors Influencing Clinicians' Choice of Adjuvant S-1 versus Capecitabine plus Oxaliplatin after Curative Gastrectomy in Patients with Gastric Cancer. J Cancer. 2016; 7:17111715.

19. Koizumi W, Narahara H, Hara T, Takagane A, Akiya T, Takagi M, Miyashita K, Nishizaki T, Kobayashi O, Takiyama W, Toh Y, Nagaie T, Takagi S, et al. S-1 plus cisplatin versus S-1 alone for first-line treatment of advanced gastric cancer (SPIRITS trial): a phase III trial. Lancet Oncol. 2008; 9:215-221.

20. Al-Batran SE, Hartmann JT, Probst S, Schmalenberg H, Hollerbach S, Hofheinz R, Rethwisch V, Seipelt G, Homann N, Wilhelm G, Schuch G, Stoehlmacher J, Derigs $\mathrm{HG}$, et al. Phase III trial in metastatic gastroesophageal adenocarcinoma with fluorouracil, leucovorin plus either oxaliplatin or cisplatin: a study of the Arbeitsgemeinschaft Internistische Onkologie. J Clin Oncol. 2008; 26:14351442 .
21. Kang YK, Kang WK, Shin DB, Chen J, Xiong J, Wang J, Lichinitser M, Guan Z, Khasanov R, Zheng L, Philco-Salas M, Suarez T, Santamaria J, et al. Capecitabine/cisplatin versus 5-fluorouracil/cisplatin as first-line therapy in patients with advanced gastric cancer: a randomised phase III noninferiority trial. Ann Oncol. 2009; 20:666-673.

22. Deng J, Liang H, Wang D, Sun D, Pan Y, Liu Y. Investigation of the recurrence patterns of gastric cancer following a curative resection. Surg today. 2011;41:210-5.

23. Oba K, Paoletti X, Alberts S, Bang YJ, Benedetti J, Bleiberg H, Catalano P, Lordick F, Michiels S, Morita S, Ohashi Y, Pignon JP, Rougier P, et al. Disease-free survival as a surrogate for overall survival in adjuvant trials of gastric cancer: a meta-analysis. J Natl Cancer Inst. 2013; 105:16001607. 